\title{
Detailed Modelling of the Masonry Unit-Mortar Interface Using Hygrothermal Simulation
}

\author{
Michael Gutland, Scott Bucking and Mario Santana Quintero \\ Department of Civil and Environmental Engineering, Carleton University, Ottawa Ontario, Canada, \\ michaelgutland@cmail.carleton.ca
}

\begin{abstract}
Hygrothermal models are important tool for assessing the risk of moisture-related decay mechanisms in historic masonry structures. However, there are significant uncertainties in the process related to material properties, boundary conditions and quality of construction that effect confidence in the model's predictions compared to measured values. This paper examines one potential source of uncertainty; the imperfect nature of mortar joints in masonry walls, exemplified by such things as open joints, hairline cracks and imperfect bonds at the interface between mortar and unit. These are rarely considered in hygrothermal modelling in detail, where perfect interfaces are typically inferred. The premise is that at this interface, liquid transport behaviour is more similar to that of a fracture than that of a bundle of capillaries. These fractures of varying heights (or aperture) can affect transport into and out of the plane of the wall (perpendicular plane) and impede the liquid transport between mortar and the masonry unit (in-plane). This could lead to the "effective" moisture transport being different than what would be predicted using measured bulk material properties. A more detailed method for modelling this interface, borrowing techniques from the field of geohydrology is presented which demonstrates the effect that detailed modelling of the mortar joint has on moisture transport in masonry. A brick wall with cement mortar is studied. A twodimensional hygrothermal model was created to demonstrate the effect of increased liquid conductivity into the wall cause by fractures.
\end{abstract}

Keywords: Masonry, Hygrothermal Simulation, Moisture Transport, Calibration, Mortar.

\section{Introduction}

Hygrothermal models are an important tool for assessing the risk of moisture-related decay such as biological growth (mould and wood rot fungi), corrosion and freeze-thaw action in building envelopes. There are several gaps in our understanding and application of hygrothermal modelling involving uncertainty of material properties, boundary conditions, two-dimensional interactions and quality of construction. This can make it difficult to calibrate hygrothermal models to in-situ measurements and without calibration, our confidence in a hygrothermal model's predictions is lessened.

This paper examines one potential source of uncertainty; namely, the imperfect interface between mortar and the masonry unit. Imperfections may take the form of open joints (mm range), hairline cracks ( $\mu \mathrm{m}$ range), or an imperfect bond between the mortar and the unit (Figure 1). These can be caused by structural displacements, shrinkage, decay/maintenance or inherent from its construction. It is intuitive to assume that a large presence of these openings will increase moisture transfer into the wall caused by wind-driven rain. The question is how much 
and how do we properly account for this in hygrothermal simulations?

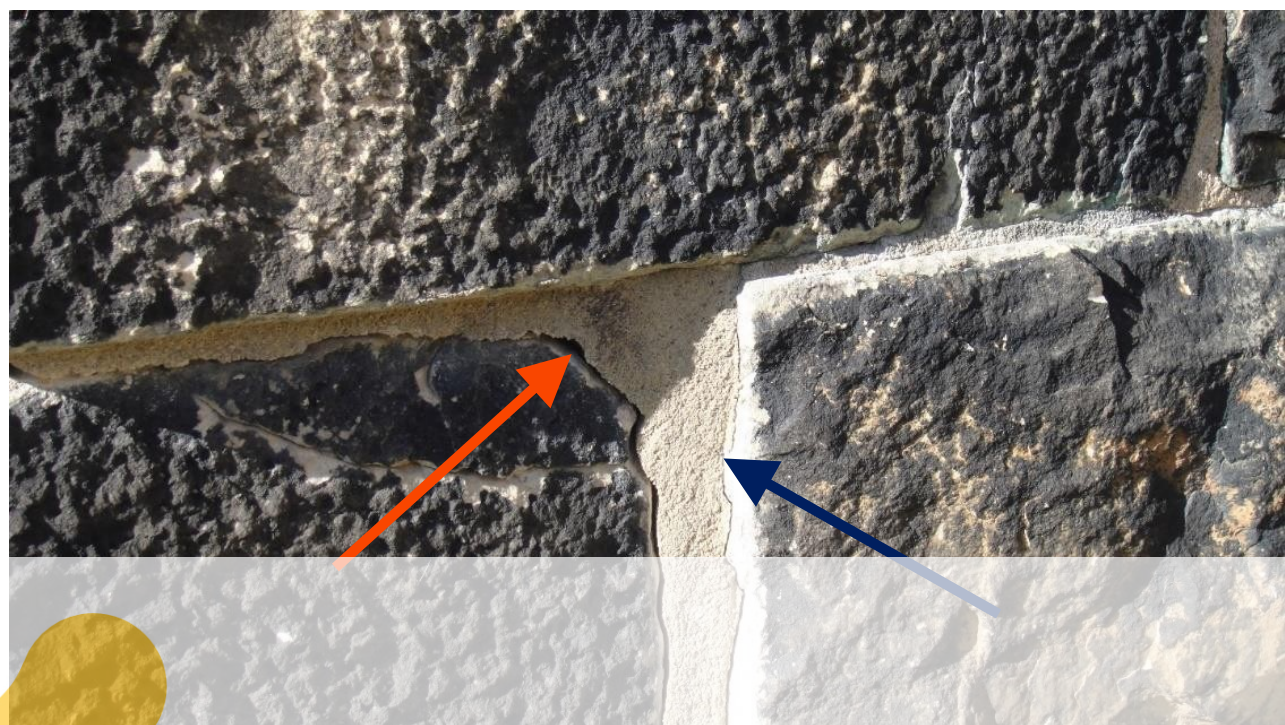

Figure 1. Sandstone masonry wall with open joint (Orange arrow) and hairline crack (dark blue arrow) between stone and mortar.

This paper proposes a methodology for explicitly modelling imperfections at the masonry

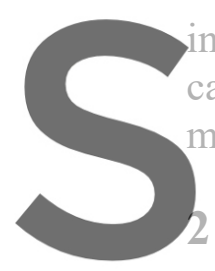

nterface by modelling this region

called aperture). Materia

moisture retention and lic

Literature Review
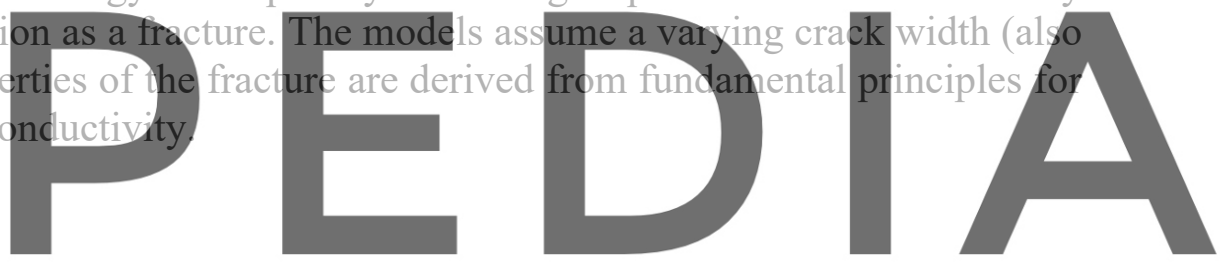

Hygrothermal modelling software simulates the coupled heat and moisture flow (vapour and

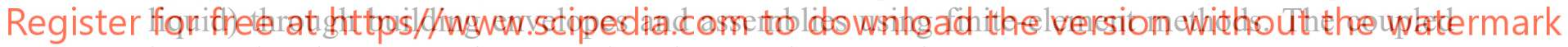

heat and moisture equations are given in Equations 1 and 2:

$$
\begin{gathered}
\frac{\partial H}{\partial t}=-\nabla\left[\lambda \nabla T+h_{v}\left(k_{v} \nabla P_{v}\right)+h_{l}\left(k_{l} \nabla P_{c}\right)\right] \\
\frac{\partial w}{\partial t}=-\nabla\left(k_{v} \nabla P_{v}+k_{l} \nabla P_{c}\right)
\end{gathered}
$$

Of particular interest to this paper is the term for liquid conductivity $k_{l}$. This controls the rate of liquid water ingress into a material by a capillary pressure gradient. Liquid conductivity is a function of moisture content and can be estimated from water absorption tests or pressure plate apparatus.

\subsection{Masonry Interface}

Previous studies have looked at moisture transfer at the interface and have shown that there is an interface resistance $\left(\mathrm{R}_{\mathrm{IF}}\right)$ which inhibits transfer from one material to the other. This is analogous to contact resistances in the heat transfer of electronics. The presence of an interface resistance is caused by one of two reasons. The first is an imperfect contact between the two materials which forces water to travel across the interface through vapour diffusion instead of 
the faster capillary method. The second reason is migration of fine particles toward the mortar joint during the curing stages (Brocken, 1998). The fine particles form smaller pores near the interface, and this reduces liquid flow.

Laboratory testing has measured the interface resistance between $1.0 \mathrm{E} 08$ and $1.0 \mathrm{E} 12 \mathrm{~m} / \mathrm{s}$ (Calle, De Kock, Cnudde, and Van den Bossche, 2019; Derluyn, Janssen, and Carmeliet, 2011; Qiu, Haghighat, and Kumaran, 2003). Simulations have demonstrated the effect that the interface resistance have on moisture uptake (Vereecken and Roels, 2013; Zhou, Desmarais, Vontobel, Carmeliet, and Derome, 2018). These methods only consider moisture transfer across the interface and not parallel to it.

\subsection{Fractures in Masonry}

There have been previous studies exploring water uptake in fractured building materials. Roels (2003) examined water uptake in a fractured brick sample and Rouchier (2012) modelled a detailed 2D crack network in a sample of concrete. Both studies required a detailed geometry of the fracture to be defined and meshed into a finite - element model. This is time and computationally expensive. It is also highly unfeasible to do on anything greater than a small sample. Modelling with an assumed fracture width will remove this need.

These simulations were also done on homogenous materials, meaning that the material was the same either side of the fracture. In a masonry interface that is not true as the material properties of the two adjacent materials may be quite different. These studies also looked

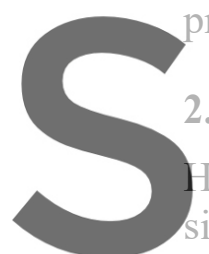

$$
\Delta P=\frac{2 \gamma \cos \theta}{r}
$$

If the capillary suction pressure is greater than this, a capillary with this radius will not be filled. The Kelvin Equation describes the relationship between vapour pressure and condensation inside the capillary:

$$
\operatorname{LN}\left(\frac{p}{p_{s a t}}\right)=\frac{2 \mathrm{rV}_{\mathrm{M}}}{\mathrm{RRT}}
$$

These equations combined with the pore size distribution allow for construction of the moisture retention curve, describing the relationship between saturation and capillary suction pressure. Narrower pores retain moisture longer and larger pores catch and release moisture more easily.

Moisture retention curves can be measured in the laboratory or estimated with the Van Genuchten equation, where $\alpha$ and $\mathrm{n}$ are material- specific parameters (van Genuchten, 1980).

$$
P_{c}=\frac{1}{\alpha}\left[S_{e f f}^{-\left(\frac{n}{n-1}\right)}-1\right]^{\frac{1}{n}}
$$


Liquid Conductivity is also a function of the capillary radius and can be calculated through the Hagen-Poiseuille equation:

$$
k_{l}=\frac{\rho r^{2}}{8 \eta_{l}}
$$

Liquid transport only occurs when capillaries are filled. Therefore, liquid conductivity is a function of saturation and exponentially increases with saturation. The moisture-dependent conductivity $\mathrm{k}_{1}\left(\theta_{1}\right)$ can be estimated by integrating the Hagen-Poiseuille over the range of active capillaries or by using the Burdine relative permeability approach (Burdine, 1953).

$$
k_{l}\left(\theta_{l}\right)=\frac{\rho}{\tau} \int_{R_{\min }}^{R} \frac{\pi r^{4}}{8 \mu_{l}} \frac{d n}{d r} d r
$$

The theoretical curve will not match the measured liquid conductivity curves (Scheffler, Grunewald, and Häupl, 2004). Tortuosity $(\tau)$ is included in this equation to account for the reduction in flow due to tortuosity, pore shape and the degree of interconnectivity of pores.

Likewise, vapour diffusion can be estimated from fundamentals, but is not discussed here.

Determining the hygroscopic properties of a fracture is similar to the process for determining those of capillary materials. To begin, we need to determine the size of the aperture with which liquid is flowing, similar to what is learned from the pore size distribution. Aperture $(\mathrm{h})$ is the distance between the boundary surfaces of the fracture. Apertures are not constant in real-world applications because it widens and contracts along its path and generally follows a tortuous path. There are two methods for determining an "effective" aperture. The first is to use the

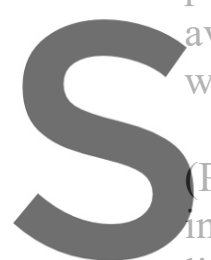
average aperture $(\bar{h})$, an vould make the cubic

Typical apertures

Pyrack-Nolte, Myer,

a similar range ((Roe

liquid transport is greatly reduced.
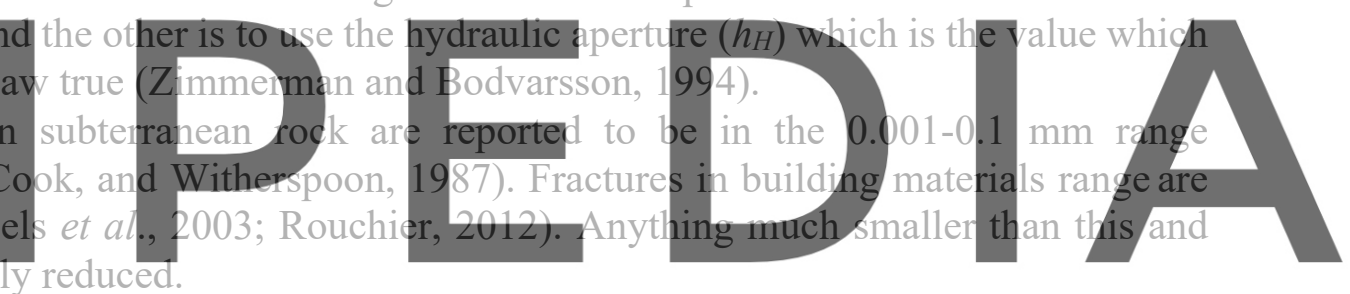

The hygroscopic material properties of the fracture can be calculated with a few distinctions

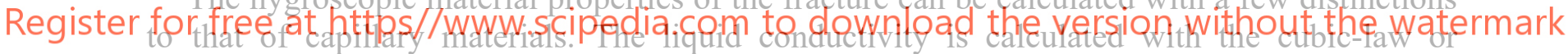
Reynold's Equation, the difference being a change in the denominator.

$$
k_{l}=\frac{\rho h^{2}}{12 \eta_{l}}
$$

Fractures can also have a much higher porosity with few obstructions. A smooth moisture retention curve can be created if an aperture distribution is assumed. The larger the aperture the further to the left the curve will be.

\section{Methodology}

DELPHIN 6.0 was used for hygrothermal simulations (Bauklimatik Dresden, 2018). DELPHIN allows input of custom material properties including direction-dependent properties, detailed moisture retention curves, and moisture-dependent liquid and vapour transfer coefficients. 


\subsection{Material Properties}

The first step was to define material properties of the masonry. Typical bulk material properties for brick and cement mortar were determined by the taking median values for all materials of its class in the DELPHIN library. The moisture retention curve for each material was estimated using a unimodal Van Genuchten with parameters $\mathrm{n}$ and $\alpha$ where calculated using least-squares regression.

Table 1. Bulk material properties used in hygrothermal simulations.

\begin{tabular}{ccc} 
Position & Clay Brick & Cement Mortar \\
\hline$\theta[--]$ & 0.294 & 0.2296 \\
\hline$\lambda[\mathrm{W} / \mathrm{m}-\mathrm{K}]$ & 0.682 & 0.723 \\
\hline$\mu[--]$ & 20.2 & 25.6 \\
\hline $\mathrm{k} \mathrm{l}$, eff $[\mathrm{s}]$ & $2.21 \mathrm{E}-09$ & $9.053 \mathrm{E}-12$ \\
\hline $\mathrm{n}[--]$ & 1.55 & 1.48 \\
\hline$\alpha[1 / \mathrm{Pa}]$ & 1.00 & 2.172
\end{tabular}

\section{The approach for creating the liquid conductivity curve was to use the theoretical curve} (Equation 7) below the capillary water content $(\theta)$ scaled by the tortuosity $(\tau)$.

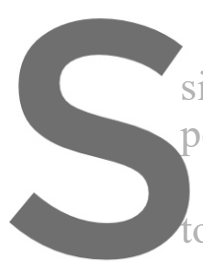

$$
\tau=\frac{k_{l}\left(\theta_{\text {cap }}\right)}{k_{l, e f f}}
$$

\section{The liquid conductiv ty} simplicity, sorption hys permeability were neglecto

The fracture materia

$10 \mu \mathrm{m}$. The fractures $\mathrm{v}$
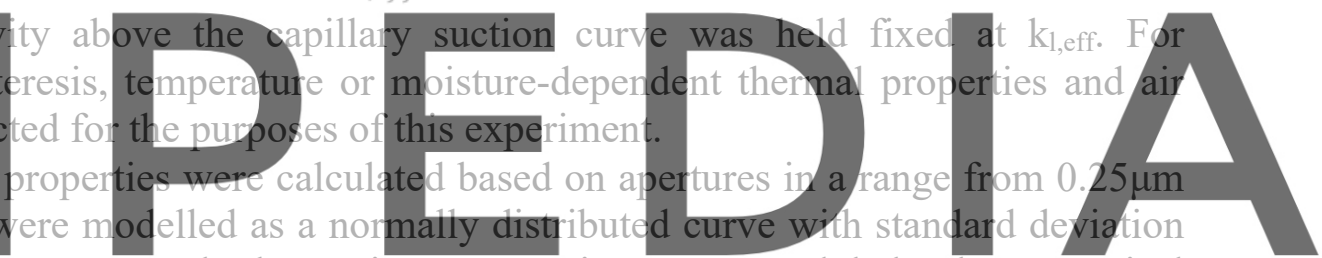

of $(\mathrm{h} / 2)$. This was done to smooth the moisture retention curve and help the numerical

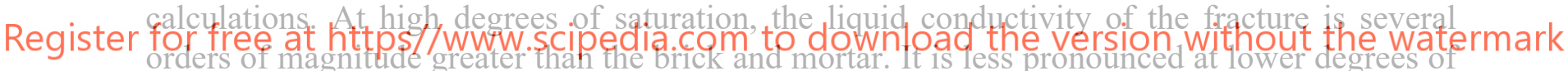
saturation. Even though the exposed area of the fracture is small it can contribute to an increase in overall moisture transport.

\subsection{Finite-Element Model}

There are three materials in the finite element model shown in Figure 2: unit, interface and mortar. The dimensions of the model (taking advantage of symmetry) are 5mm thick mortar, $x$ $\mathrm{mm}$ aperture and $28 \mathrm{~mm}$ brick. The width of the assembly is $92 \mathrm{~mm}$. 


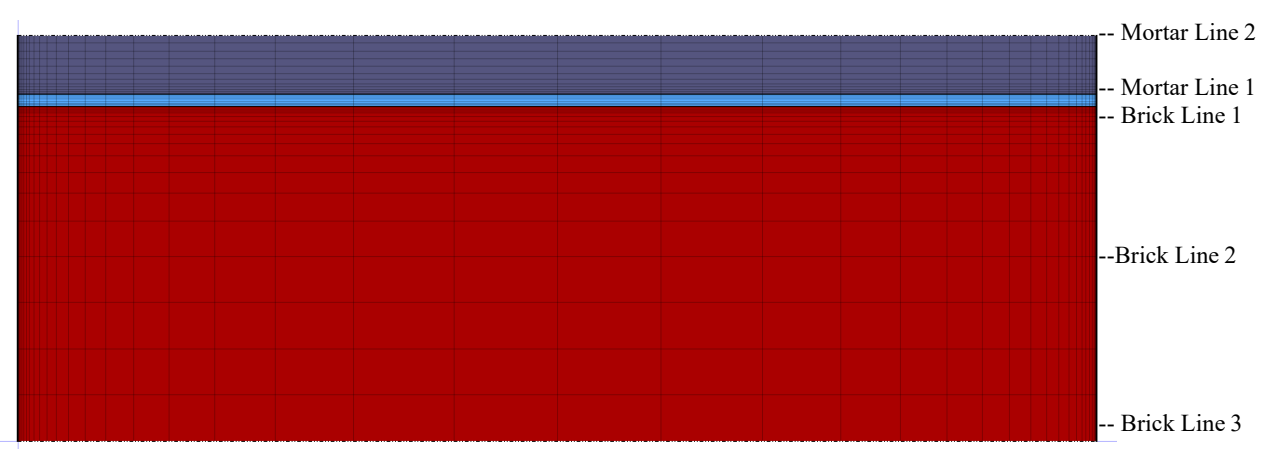

Figure 2. Finite Element Model (interface is not drawn to scale).

\subsection{Boundary and Initial Conditions}

The simulation was performed under the following boundary conditions:

1. Water Uptake - All materials set to $50 \% \mathrm{RH}$ and exposed to a capillary pressure of -

$0.025 \mathrm{~m}$ on one side only. This was done to mimic a water absorption experiment.

2. Drying - All materials are set to $99.99 \% \mathrm{RH}$ and exposed to an RH of $30 \%$ on oneside.

All other sides are adiabatic and there is no temperature gradient, sources/sinks in the model.

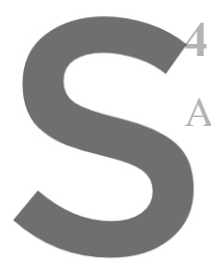

\section{Results}

A sample of the results are show

Moisture content profile

Brick Lin.
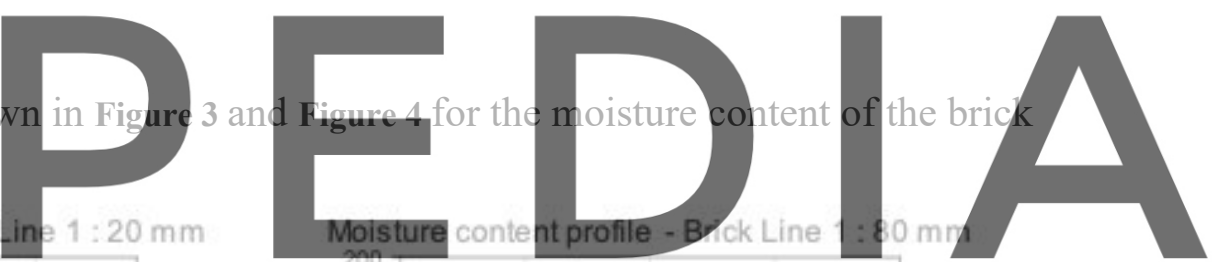

Register for free at https//www.scipedia.com to download the version without the watermark
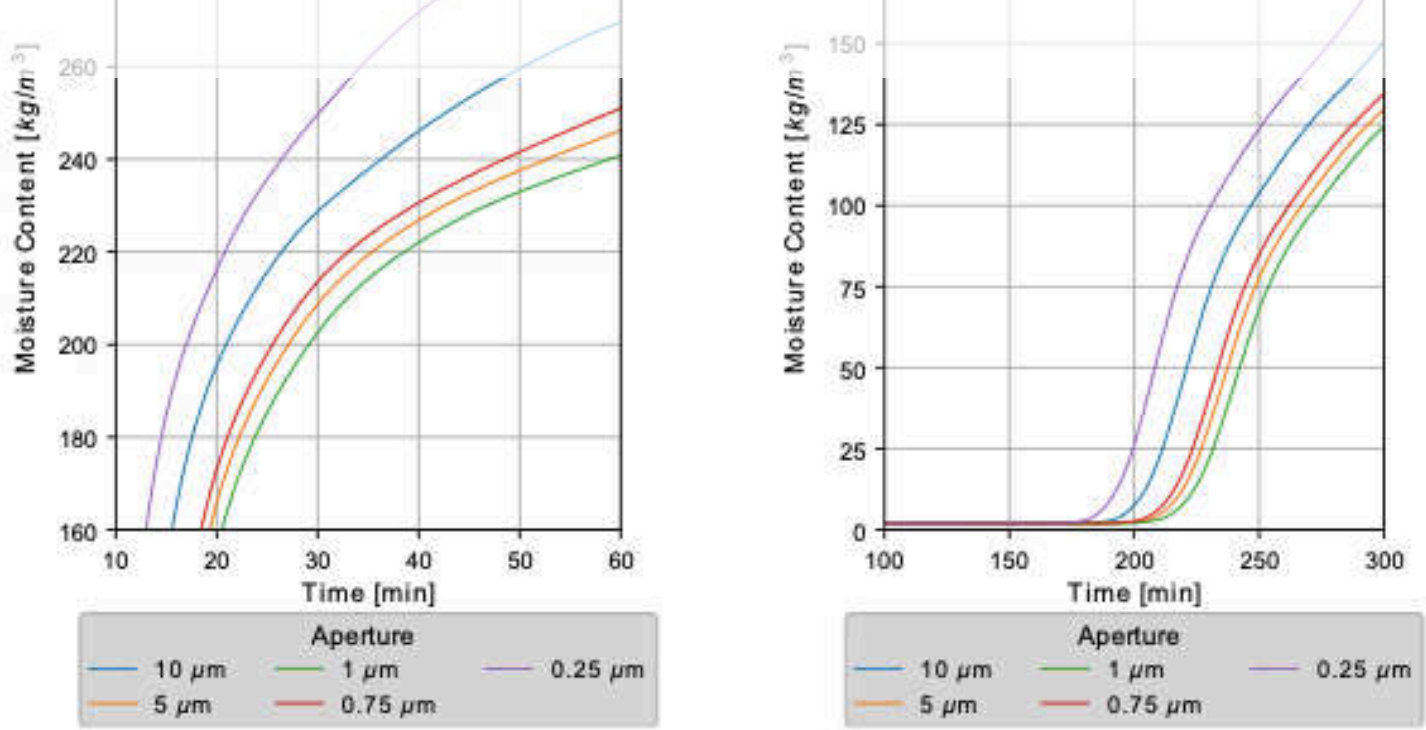

Figure 3. Moisture content of the brick adjacent to the fracture at $20 \mathrm{~mm}$ depth (left) and $80 \mathrm{~mm}$ depth (right). 

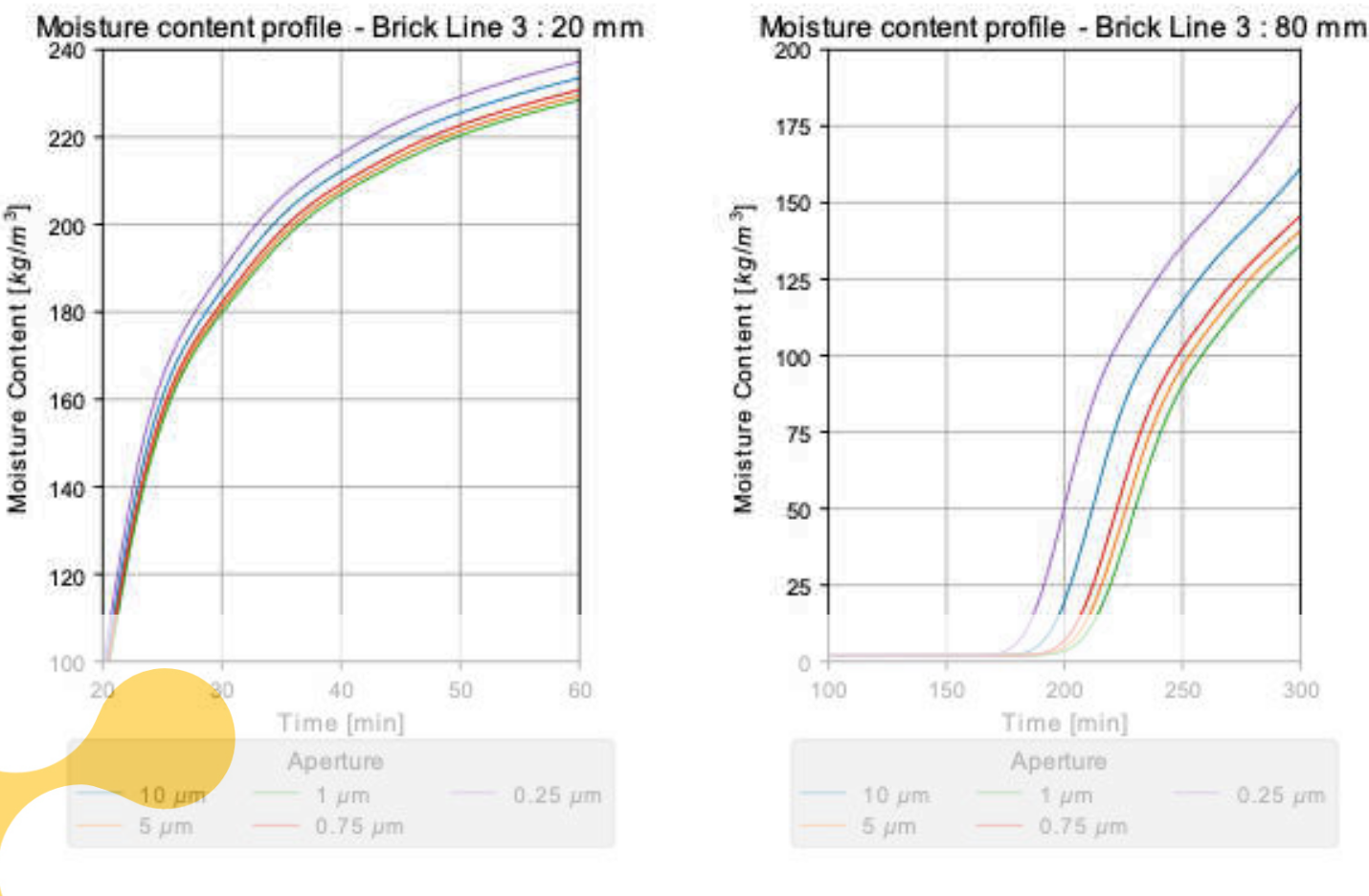

Figure 4. Moisture content of the brick at centreline of brick at $20 \mathrm{~mm}$ depth (left) and $80 \mathrm{~mm}$ depth (right).

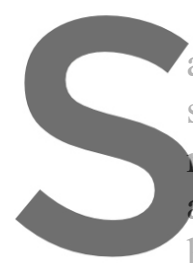

djacent to the fracturte

significant change in no
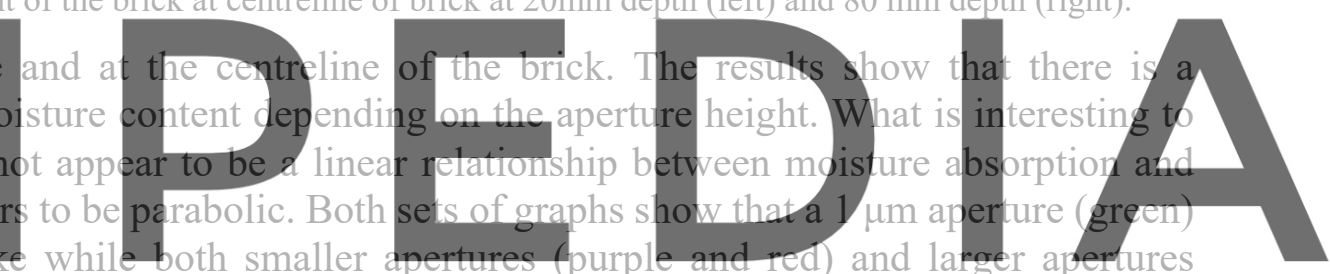

(blue and orange) have increased absorption. The smaller apertures, while having a lower

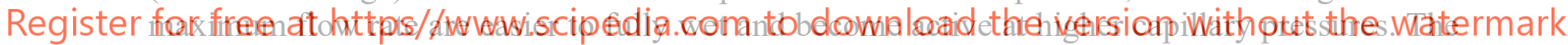

larger apertures need extremely low (and in the reality of building walls, extremely rare)

capillary pressures to become active and allow liquid to flow. The effect was noticeable adjacent to the fracture and the centre of the unit.

The simulation was performed on a sandstone/lime mortar combination with roughly twice the material dimensions. The results were not as pronounced as the case of brick/cement mortar combination. The impact of the fracture appears to be dependent on bulk material properties and the relative area density of the interfaces.

The drying simulation was performed over the course of one calendar year. The effect of the fracture was found to be minimal with a reduction in $\mathrm{RH}$ of less than $1 \%$ at the centre of the brick. It was determined that any enhancement to vapour diffusion out through the fracture was minimal.

\section{Conclusion}

The results of the DELPHIN simulations show that modelling imperfections at the masonry interface explicitly as fractures can affect simulation results compared to using only bulk material properties. The presence of fractures greatly increases the liquid conductivity locally 
in a fashion similar to a thermal bridge. Future work will look at incorporating an anisotropic model into the fracture interface to account for interface resistances across the fractures as well as under more realistic boundary conditions such as typical meteorological years. Further research needs to be done to determine what the range of apertures are common in masonry walls and correlate the models to experimental data. The goal is to determine "effective" moisture transport coefficients which take into consideration imperfections and twodimensional interactions which can be used by practitioners.

\section{ORCID}

Michael Gutland: https://orcid.org/0000-0001-8907-4046

Mario Santana Quintero: https://orcid.org/0000-0002-3836-9714

Scott Bucking: https://orcid.org/0000-0002-3237-183X

\section{References}

Bauklimatik Dresden. (2018). DELPHIN 6.0 (Version 6.0.18). Dresden.

Brocken, H.J.P. (1998). Moisture transport in brick masonry: The grey area between bricks (Dissertation). Technische Universiteit Eindhoven.

Burdine, N.T. (1953). Relative Permeability Calculations From Pore Size Distribution Data. SPE-225-G, 5(03), $71-$ 78. https://doi.org/10.2118/225-G

Calle, K., De Kock, T., Cnudde, V. and Van den Bossche, N. (2019). Liquid moisture transport in combined ceramic brick and natural hydraulic lime mortar samples: Does the hygric interface resistance dominate the moisture transport? Journal of Building Physics, 43(3), 208-228. https://oi.org/10.1177/1744259119857762

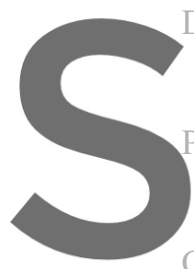

Derluyn, H., Janssen, H. al

in layered materia https://doi.org/10.1016

yrack-Nolte, L.J., Myer,

properties of natural fract

Lab., CA (USA). Retriever
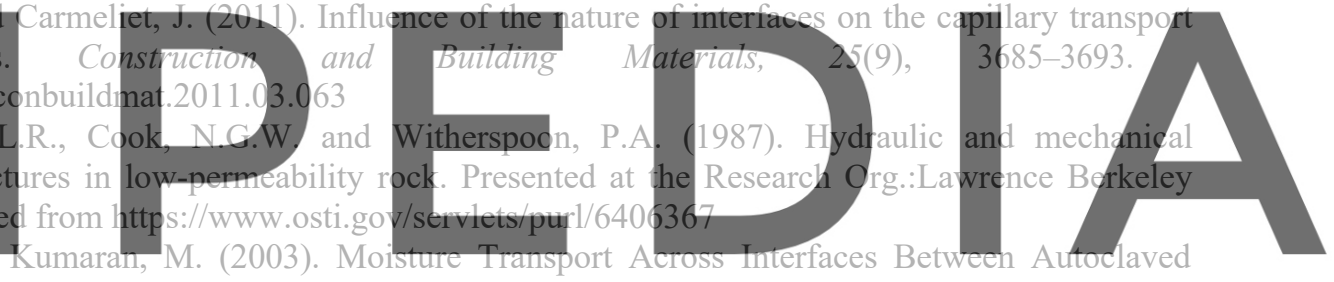

Aerated Concrete and Mortar. Journal of Building Physics, 26. https://doi.org/10.1177/109719603032804

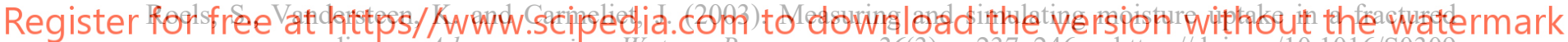
porous medium. Advances in Water Resources, 26(3), 237-246. https://doi.org/10.1016/S0309 1708(02)00185-9

Rouchier, S. (2012). Hygrothermal performance assessment of damaged building materiais (Doctorate, Université de Lyon). https://doi.org/10.13140/rg.2.1.1532.4561

Scheffler, G., Grunewald, J. and Häupl, P. (2004). Calibration of an engineering model of hygrothermal material characterisation. Council for Research and Innovation in Building and Construction W40 Meeting. Presented at the Glasgow, Scotland. Glasgow, Scotland: Council for Research and Innovation in Building and Construction.

Van Genuchten, Martinus. Th. (1980). A Closed-form Equation for Predicting the Hydraulic Conductivity of Unsaturated Soils1. Soil Science Society of America Journal, 44(5), 892. https://doi.org/10.2136/sssaj1980.03615995004400050002x

Vereecken, E. and Roels, S. (2013). Hygric performance of a massive masonry wall: How do the mortar joints influence the moisture flux? Construction and Building Materials, 41, 697-707. https://doi.org/10.1016/j.conbuildmat.2012.12.024

Zhou, X., Desmarais, G., Vontobel, P., Carmeliet, J. and Derome, D. (2018). Water uptake in masonry: Effect of brick/mortar interface. 7th International Building Physics Conference Proceedings, 103-108. Syracuse.

Zimmerman, R.W. and Bodvarsson, G.S. (1994). Hydraulic Conductivity of Rock Fractures. Lawrence Berkley Laboratory. 